Talves, K., \& Kalmus, V. (2015). Gendered mediation of children's internet use: A keyhole for looking into changing socialization practices. Cyberpsychology: Journal of Psychosocial Research on Cyberspace, 9(1), article 4. doi: 10.5817/CP2015-1-4

\title{
Gendered mediation of children's internet use: A keyhole for looking into changing socialization practices
}

\author{
Kairi Talves ${ }^{1}$, Veronika Kalmus ${ }^{2}$ \\ ${ }^{1,2}$ Institute of Social Studies, University of Tartu, Tartu, Estonia
}

\begin{abstract}
This study focuses on parental mediation of children's internet use in the context of broader gendered socialization patterns. Analyses were carried out in three steps using quantitative and qualitative methods. Firstly, based on EU Kids Online survey data, gendered patterns in parental mediation across European countries were explored. Secondly, detailed analysis of mediation practices in Estonia, one country in the EU Kids Online survey, was carried out. As the last step, data from two focus group interviews were used for in-depth analysis of Estonian mothers' everyday practices of mediating their children's internet use. Quantitative analysis revealed significant correlations between the number of gender differences in parental mediation, and country-level variables of internet penetration and gender equality. In Estonia, as a country with low gender equality, but high internet use, mediation strategies do not depend purely on children's gender, but on a more complex interrelation of gender and children's and parents' socio-demographic characteristics and parent-child interactions. This finding was supported and explained by qualitative analysis, showing that Estonian mothers' methods for mediating boys' and girls' internet use differ in several aspects, reflecting the broader context of changing socialization practices, gender norms, and the generation gap in using digital technologies.
\end{abstract}

Keywords: Parental mediation; socialization; gender ideologies; cultural values

\section{Introduction}

The concept of social mediation originates in socialization theory, which is related to the research fields of media socialization and media literacy. This study focuses on parental mediation of children's internet use, defined for our research purposes as 'regulatory strategies that parents introduce to maximise benefits and minimise risks for their children' (Kirwil, Garmendia, Garitaonandia, \& Martínez Fernández, 2009). Parental mediation of children's internet use is often considered as a 'new' or 'specific' type of parenting. Technology mediation is a challenge for many parents as they did not grow up with the internet. Consequently, many parents do not feel confident supervising their children's technology usage (Kalmus \& Roosalu, 2012). However, recent studies are looking beyond the technological rootedness of parental mediation of internet use, viewing it as part of socialization processes guided by broader cultural ideologies and models of raising children (Kirwil, 2009). Socialization practices are also embedded within gender ideologies that influence the values and methods involved in raising sons and daughters. Gendered socialization aims and norms can be assumed to be particularly strong in technology-related fields where cultural stereotypes about gender and technology intersect.

The novelty of this study consists in exploring gender patterns of parental mediation both on the macroand the micro level, keeping in mind the mutuality of transformations (Hedström \& Swedberg, 1998) between cultural ideologies and socialization practices. We address parental mediation of children's internet use as an empirically tangible part of broader socialization patterns, presumably interacting with gendered representations and norms of ICT use. First, we use EU Kids Online survey data to explore gender patterns of parental mediation and the related contextual factors across 25 European countries. 
Secondly, we take a closer look at one European country for detailed quantitative and qualitative analyses of the interplay between gender and other aspects of parental mediation within a particular cultural context. We focus on Estonia as a country that has gone through remarkable economic, technological, and social transformations during the last decades. The changes, however, have affected different social groups at varying pace, creating contradictions in the value system (Lauristin, 2003) and, in particular, asynchronicity in the entrainment of different generations by transformations (including 'internetization'), presenting challenges to older generations in fulfilling their socializing role. EU Kids Online survey results show that Estonian children are benefiting from their high use of the internet, but they are also leading the European rankings in excessive internet use and harmful online experiences (Kalmus, 2013). Estonian parents are, at the same time, relatively untroubled and passive in supervising or restricting their children's online activities. Furthermore, Estonian parents are struggling between different and often contradictory socialization values, such as old (authoritarian, child obedience-oriented) and new (liberal, child autonomy-oriented) parenting paradigms and gender norms (Tulviste, Mizera, \& De Geer, 2012).

\section{Theoretical and Empirical Background}

\section{Social Mediation of Children's Internet Use}

In its essence, 'social mediation' is a multidimensional, higher-order construct that embraces a considerable variety of types of social interactions between children and socialising agents, as well as specific child-rearing techniques, practices, and strategies employed within families (Chakroff \& Nathanson, 2011; Kirwil, 2009). On a broader level of generalization, the social mediation of children's internet use can be divided into two categories: social support, i.e. help, guidance, co-use and cointerpreting, and rules and restrictions (Kalmus, 2012). On a more concrete level, several typologies of parental strategies for mediating children's internet use have been proposed, most common of them being a quadripartite categorisation, distinguishing between 'active co-use' and three types of 'restrictive mediation' (use of technical filtering/ monitoring tools, setting rules and restrictions, and monitoring of visited websites and received/ sent e-mails; Livingstone \& Helsper, 2008).

Rooted within socialization theory, social mediation is contextualised in relation to socialization cultures, guided by morals and values (Kirwil et al., 2009). Social mediation of children's internet use carries a heavy contextual loading, which needs to be carefully considered and interpreted. Macro-level analyses have shown that parental mediation of children's internet use is influenced, for instance, by the countries' cultural orientation in terms of individualistic and collectivistic values (Kirwil, 2009), and welfare and gender regimes (Kalmus \& Roosalu, 2012). Furthermore, previous studies have demonstrated that the differences and similarities in parental mediation among countries are at least partly based on diffusion rates, and parents' online experience and technological opportunities, which in turn are related to national wealth (Helsper, Kalmus, Hasebrink, Sagvari, \& de Haan, 2013). As gender aspects of socialization are heavily dependent on cultural contexts, we expect to find considerable variety in gendered patterns of parental mediation across 25 European countries.

Macro determinants within countries, such as class position and educational background, play a significant role in shaping the capabilities of parents to engage in the media socialization of their children. In general, better-educated parents tend to support their children through more active mediation, whereas lowereducated and socially disadvantaged families rely more on restrictive regulations as parents have less time and competences to assist their children through face-to-face discussion (Paus-Hasebrink, Ponte, Dürager, \& Bauwens, 2012).

Socio-demographic, in particular age and gender, and cognitive characteristics (e.g. digital skills) of parents and children are predictors of the occurrence of different types of mediation. Studies (e.g. Kirwil et al., 2009) report that parental mediation, in general, decreases as children get older, and that mothers are more involved in mediation than fathers. Previous analyses of the EU Kids Online survey data have also focused on gender patterns in parental mediation of children's internet use. The analysis of single indicators did not reveal many differences between boys and girls (Livingstone, Haddon, Görzig, \& Ólafsson, 2011). However, the comparison of the mean values of composite measures (the indexes of parental mediation) demonstrated that girls received more of all types of parental mediation except technical restrictions; furthermore, girls attributed slightly greater authority to their parents in internetrelated matters (Livingstone, Kalmus, \& Talves, 2014).

Many recent micro-level studies view social mediation as being tightly related to or forming part of overall parenting styles and communication and relationships patterns in families (Eastin, Greenberg, \& Hofschire, 2006; Rosen, Cheever, \& Carrier, 2008). It has even been suggested that mediation may be a surrogate measure for the quality of the parent-child relationship, related to parental involvement with 
children (Chakroff \& Nathanson, 2011). To avoid the social-reductionist perspective on media socialization, it is crucial to take into account psychological aspects, such as confidence, trust, selfesteem, and self-worth in parent-child interactions (Paus-Hasebrink et al., 2012) when analysing gender patterns of parental mediation.

Lastly, previous research has demonstrated that parents choose mediation strategies in accordance with their positive or negative expectations of media effects on children. For instance, parents who are concerned about media-related risks and harm take steps to protect their children by applying restrictions on media use, and monitoring or supervising the child, whereas parents who see the media as offering educational or entertainment opportunities more frequently co-use the media with children or discuss the media content (see Nikken \& Schols, 2015, for an overview). Furthermore, research has suggested that parents may adjust their mediation strategies retroactively in reaction to children's negative online experience (Kalmus, von Feilitzen, \& Siibak, 2012).

While the gender of parents and children has been included among independent variables in most of the previous studies, research on the interplay between gender and other socio-demographic and cognitive characteristics in shaping parental mediation strategies is scarce. In focusing on such interplay within a particular cultural context, we expect to find somewhat different determinants of mediation strategies for sons versus daughters. For instance, in the case of boys, parents' confidence in using the internet may play a more important role.

\section{Changing Socialization Practices in Estonia}

In recent decades, Estonian society has faced rapid changes in the economic, political, and social spheres. The collapse of the Soviet Union opened the way for ideological changes by pushing the society toward Western values, such as rising individualism, self-actualization, autonomy, and self-reliance (Lauristin, 1997). Societal and cultural transformations and asymmetrical development of different value items have led to the mixture of different 'transitions' and a growing gap between older and younger generations (Raudsepp, Tart, \& Heinla, 2013). The generation gap is especially visible in the context of technological changes (e.g. internetization), which, in turn, impacts inter-generational relations, affecting parenting practices and communication patterns in family.

In a new socio-political context, family as an institution has undergone dramatic changes. Family relationships have become relatively fragile, characterized by the rise of unmarried cohabitations and high divorce rates. Today, more and more children are raised in single-parent or reconstituted families, which weakens the bonds between parents and children, and affects parenting styles. Relationships between children and parents are transforming from parental dominance toward democratic negotiations with children, and changing societal norms increasingly urge parents to be responsible for one's decisions. These developments have made the choice of parenting methods more complex (Kutsar, Kasearu, \& Kurrikoff, 2012).

The troubled nature of parenting in Estonia is confirmed by a more recent study. Tulviste et al. (2012) compared the socialization values of Estonian and Swedish mothers and found that Estonian mothers' values can be characterized by a struggle between authoritarian and liberal parenting paradigms, while Swedish mothers steadily value a liberal style. Estonians put a lot of emphasis on children's conformity and obedience as well as on being trustworthy and hardworking, while Swedes stress the importance of believing in one's own abilities and self-direction. The authors argue that although the current socioeconomic situation in Estonia has become more stable, traditional socialization values have not made way to liberal endeavours in socialization. Instead, the co-existence and mixture of different values are about to prevail.

While socialization values in Estonia are slightly changing, gender roles do not appear to be changing much. According to Gender Equality Monitoring 2013 (Aavik \& Uusma, 2014), only 21\% of Estonians think that boys and girls should acquire similar attributes and skills when growing up. The most important and gender-neutral socialization outcome is financial literacy: $45 \%$ of respondents considered it relevant for boys and $44 \%$ for girls. Other attributes are more or less gender specific, reflecting strongly traditional views on male and female roles in society. Most notable differences appear in attitudes concerning technical skills: while Estonians tend to think that handling technical equipment $(36 \%)$ and driving a car (34\%) are important proficiencies to be taught to boys, only a minor part of respondents ( $4 \%$ and $9 \%$, respectively) consider these skills relevant for girls. The same survey shows, contrary to expectations, that the youngest generation, 15-19 year olds, is in many aspects a bit more traditional compared with older age groups (Aavik \& Uusma, 2014). Thus, Estonians tend to uphold gender stereotypes in 
socialization quite persistently, and the worlds of boys and girls are still largely distinguished as two separate realities.

\section{Methods}

\section{EU Kids Online Survey}

In the first two sections of empirical analysis dealing with gendered mediation in the cross-cultural context and gender patterns of parental mediation in Estonia, we use data from the EU Kids Online survey - the only representative cross-national dataset that includes a comprehensive list of matched questions about parental mediation of children's internet use asked of the child and the parent.

\section{Participants}

A random stratified sample of 1000 internet-using children aged 9-16, and one of their parents was interviewed in each of 25 European countries (see Livingstone et al., 2011 for the details). Special attention was paid to ensure that the differences between countries were not caused by the methodology used. To minimise biases and maximise equivalence (van de Vijver \& Leung, 2011), several a priori procedures were used (Görzig, 2012). The questionnaire, translated and back-translated from English into 24 languages, underwent first cognitive testing and then pilot testing to enhance comprehensibility. Several items and scales were supported by country-specific examples and culture-specific concepts. Data collection was adapted to the best national practices and was conducted by a single agency, employing specially trained interviewers in all 25 countries. Interviews took place during spring and summer 2010 in children's homes. They were conducted face to face, supplemented with private questionnaire completion for sensitive questions. Further methodological details are provided in Livingstone et al. (2011), Görzig (2012), and on www.eukidsonline.net.

\section{Measures}

Questions about parental mediation, asked of children and one of their parents, were recoded into binary yes/no options and grouped into five indexes (see Table A1 in Appendix).

To find out the determinants of mediation strategies for sons versus daughters, we used the following predictors in linear regression models:

Socio-demographic variables: gender of parent; age of parent; age of child (both measured in years). As the measure of socioeconomic conditions we used socioeconomic status of household that combines the level of education and occupation of the head of household (1 - low to 3 - high). As previous research has pointed at some differences in online experiences and parental mediation between Estonian-speaking and Russian-speaking children in Estonia (Soo, Ainsaar \& Kalmus, 2012), we included the variable Estonian spoken as a main language at home (yes/no).

Among cognitive and psychological variables we included three measures of parental confidence: how confident the parent is in using the internet (1 - not at all confident to 4 - very confident); confidence in being able to help the child - to what extent the parent feels to be able to help the child to deal with anything on the internet that bothers them (1 - not at all to $4-$ a lot); confidence in the child's selfefficacy - to what extent the parent thinks the child is able to deal with things on the internet that bother him or her ( 1 - not at all to 4 - a lot).

The indicators of expectations / experiences of media effects include: parent's internet-related worries, measured by the index of two binary variables: whether the parent worries a lot about the child seeing inappropriate material on the internet (yes/no) and whether the parent worries a lot about the child being contacted by strangers on the internet (yes/no); and child's harmful online experiences whether the child had seen or experienced anything on the internet in the past 12 months that bothered or upset him or her in any way (yes/no). 


\section{Focus Group Interviews}

\section{Participants}

Two focus group interviews were conducted with Estonian parents. The first interview $(N=9)$ took place in December 2012 face-to-face, and the other $(N=6)$ in March 2014 in an online chat room. We used strategic sampling (Trost, 1986) with the homogeneity of groups in terms of socio-economic background and the family composition (at least one child aged 9-12) as the main criterion. The homogeneous composition of focus groups allows for more free-flowing conversation between participants and makes it more comfortable to discuss the topic easily in normal day-to-day interaction (Morgan, 1997). To recruit participants, we used convenience sampling, which assumes a rather homogeneous population and can provide a great source of rich verbatim comments on specific cases (Patton, 2002). The sample is purposefully heterogeneous regarding children's gender: five respondents have daughters and ten respondents have sons. We tried to achieve heterogeneity in terms of parents' gender; however, none of the contacted fathers agreed to participate in the interviews. For each respondent, we use codes (e.g. F1.5B10), where the first digits mark the number of the focus group and the respondent, the middle letter marks the gender $(B / G)$ and last digits the age of the child.

\section{Data analysis}

We used two-step qualitative content analysis (Mayring, 2000), following the steps of deductive and inductive category assignment regarding the types of parental mediation. First, we created deductive categories based on the typologies of parental mediation used in previous studies (e.g. Livingstone \& Helsper, 2008), and identified the main types of parental activities that mothers stressed in the focus group interviews. Secondly, we used inductive category development by separating the answers of boys' and girls' mothers and identifying the expressions that mothers used for describing their sons' and daughters' internet use, their assumptions and attitudes with regard to this, and mediation practices applied for boys and girls. We turned special attention to 'hidden agenda' (Flick, 2014) by looking carefully for topics that were expressed by boys' mothers while missing in the utterances of girls' mothers, and vice versa. Throughout the whole coding procedure we used multiple iterations in creating categories and inter-coder verification (only the codes that both authors agreed upon were retained) to ensure transparency and reliability of coding.

\section{Results}

\section{Gendered Mediation in the Cross-Cultural Context}

In the EU Kids Online survey, matched comparison questions about parental mediation were asked of the child and the parent most involved in children's internet use. In all countries, this was overwhelmingly mothers or female caregivers (the European weighted average was $80 \%$ ). This distribution seems to be the function of a general normative assumption throughout the European cultural and geographical area and beyond, according to which women tend to bear most of the domestic caregiving responsibilities (Kalmus \& Roosalu, 2012). The share of fathers or male caregivers varies considerably between the countries, ranging from $16 \%$ in Germany to $36 \%$ in Norway. In Estonia, the share of fathers is rather low $(18 \%)$.

To analyse gender patterns of parental mediation systematically, we compared the mean values of ten indexes of mediation (five indexes based on children's answers and five indexes based on parents' answers) in all 25 countries. The resulting pattern is presented in Table A2 in Appendix. It is evident that in most countries, including Estonia, girls tend to receive more of at least one type of parental mediation. The reverse (only boys' online activities being mediated more extensively) holds just in a few countries (Finland, Lithuania, Poland and Portugal). In those cases, parents apply more restrictions and/or technical mediation (or monitoring) to boys, whereas boys never receive more active mediation. In another small group of EU member states (Cyprus, France, Hungary, Romania and the United Kingdom), no statistically significant gender differences in parental mediation exist. The overall number of gender differences varies from zero in those five countries to eight in Sweden, being at a medium level (three) in Estonia. The number of inconsistent child-parent index pairs (e.g. statistically significant gender difference in the mean index values according to children coupled with insignificant difference according to parents) ranges from zero (in nine countries) to three (in Estonia and Sweden).

To find explanations to the cross-cultural pattern of gender similarities and differences, we used correlation analysis of several country level variables (Table 1). As might be expected, the percentage of 
male caregivers among respondents is significantly correlated with the Gender Gap Index (Pearson's $r=$ $.49 ; p<.05)$ : the greater the gender equality, the higher the share of fathers among the parents most involved in children's internet use in respective countries. Furthermore, the involvement of fathers in children's media socialization tends to be higher in the countries with more advanced technological infrastructure, greater percentage of daily internet users among both parents and children, and higher occurrence of children's negative online experiences.

Table 1. Correlations of Country Level Variables $(N=25)$.

\begin{tabular}{|c|c|c|c|c|c|c|c|c|}
\hline & 1. & 2. & 3. & 4. & 5. & 6. & 7. & 8. \\
\hline 2. Inconsistent child-parent index pairs (0-3) & $.58 * *$ & 1 & & & & & & \\
\hline 3. Gender Gap Index ${ }^{1}$ & $.48^{*}$ & .35 & 1 & & & & & \\
\hline 4. Fathers among the parents most involved in child's internet use (\%) & $.55^{* *}$ & $.51^{*}$ & $.49 *$ & 1 & & & & \\
\hline 6. Children using the internet daily (\%) & .19 & $.56^{* *}$ & $.56^{* *}$ & $.44^{*}$ & $.69 * *$ & 1 & & \\
\hline 7. Children having been bothered by something online (\%) & .36 & $.62 * *$ & $.42 *$ & $.60 * *$ & $.59 * *$ & $.64 * *$ & 1 & \\
\hline 8. Broadband penetration rate ${ }^{2}$ & $.40^{*}$ & .39 & $.81^{* *}$ & $.47^{*}$ & $.87^{* *}$ & $.46^{*}$ & $.45^{*}$ & 1 \\
\hline
\end{tabular}

Notes: ${ }^{1}$ Eurostat 2009; the nearer the value is to 1.0, the smaller the gender gap is. ${ }^{2}$ Eurostat 2009; percentage of households using broadband connection.

* Correlation is significant at the 0.05 level (2-tailed); ** Correlation is significant at the 0.01 level (2-tailed).

A bit surprisingly, the number of gender differences in parental mediation is positively correlated with the Gender Gap Index $(r=.48 ; p<.05)$ and the percentage of male caregivers $(r=.55 ; p<.01)$, as well as with the broadband penetration rate $(r=.40 ; p<.05)$. It is possible, however, that in the countries where the diffusion of online technologies started earlier and where it has been more extensive and equable, parents have had more time and opportunities to reflect upon and adopt different mediation types for boys and girls.

The number of inconsistencies in aggregated child-parent answer pairs is significantly correlated with most of the variables used in this analysis. It is quite obvious that the higher the level of gender differences in mediation, the greater the very probability for inconsistencies in child-parent index pairs ( $r$ $=.58 ; p<.01$ ). Moreover, the faster the adoption of the internet is (as indicated by the share of daily users among both parents and children), the higher the likelihood for different generations to hold somewhat divergent perceptions and norms with regard to parental mediation. Such divergence, in turn, may have a bearing on the higher occurrence of children's negative online experiences.

Table 2 presents a classification of countries based on two gender dimensions of parental mediation, including the number of gender differences in ten indexes of mediation and the share of male caregivers among respondents. The resulting typology is somewhat more difficult to interpret compared to the patterns of country-level correlations discussed above.

Three countries with high percentage of fathers among respondents and high levels of gender differences in parental mediation (the Netherlands, Norway and Sweden) are all characterised by notable gender equality, encouraged by state policies. The social democratic welfare arrangement in those countries (Vis, van Kersbergen, \& Becker, 2008) fosters the spread of the double breadwinner / double caregiver family model, which, in turn, probably manifests in a more gender egalitarian pattern of parental involvement in children's internet use. The three countries also stand out by the highest broadband penetration rates (77\% or more in 2009) among the 25 European countries involved in this study, which is in line with our proposed explanation about parents having had more time and opportunities to adopt different mediation types for boys and girls. 
Level of gender differences in parental mediation

Percentage of fathers among the parents

Low (0-1)

Medium (2-5)

High (over 5) most involved in child's internet use

Low (16-21\%)

$\begin{array}{ll}\text { France } & \text { Bulgaria } \\ \text { Hungary } & \text { Estonia } \\ \text { Italy } & \text { Germany } \\ \text { Poland } & \text { Ireland } \\ \text { UK } & \text { Lithuania } \\ & \text { Turkey }\end{array}$

Medium (22-28\%)

Cyprus

Austria

Czech Republic

Finland

Slovenia

Romania

Greece

Portugal

High (29-36\%)

Belgium

Denmark

Netherlands

Norway

Sweden

Another clear pattern reveals that all eight post-socialist countries, including Estonia, are characterised by low or medium percentage of male caregivers among respondents as well as low or medium levels of gender differences in parental mediation. In terms of gender regimes, post-socialist countries have already developed in somewhat different directions (Bohle \& Greskovits, 2007). Nevertheless, those countries tend to follow the universal breadwinner model, with very few part-time options and, thus, rather egalitarian full-time labour market participation (Kalmus \& Roosalu, 2012). The predominant gender ideology, however, associates home-making and childcare almost exclusively with females (particularly in Estonia; Järviste, 2010), which seems to be reflected in relatively low shares of fathers among the parents most involved in children's internet use. The broadband penetration rates in most of the post-socialist countries are below the EU average (56\% in 2009), ranging from $24 \%$ in Romania to $62 \%$ in Estonia. This tendency, again, rather supports our hypothetical explanation, according to which the diffusion rate of new technologies, having been somewhat delayed, harsh and uneven in transition societies, has left parents in those countries with less time and opportunities for developing genderspecific mediation strategies.

\section{Gender Patterns of Parental Mediation in Estonia}

In the following analysis of the EU Kids Online survey data we focus on Estonia - a rather typical postsocialist country with a low share of fathers (18\%) among the parents most involved in children's internet use, and a medium number (three) of gender differences in the indexes of parental mediation.

Active mediation of internet use is a strategy, in which no significant gender differences appear; furthermore, in this type of mediation there is the greatest agreement between children's and parents' answers (see Table A1 in Appendix for more details).

Active mediation of internet safety is a strategy in which Estonian parents report a very similar approach to boys and girls, while boys seem to underreport parental activities - as compared to the girls' and the parents' answers. This tendency holds, in particular, with regard to parental precautions or help in the case of harmful online experiences. It is possible that boys have, to some extent, adhered to a gender norm, according to which admitting one's vulnerability and dependence on parents, especially in technology-related matters, is not appropriate.

Restrictive mediation is a strategy with very few and minor gender differences. The very existence of all types of rules, however, is either underreported by children (both boys and girls) or overreported by parents. 
Monitoring and technical mediation are, similarly to active mediation of internet safety, strategies in the case of which parents report quite a gender-neutral approach, while boys tend to admit somewhat looser parental control over their online activities.

To get an insight into the interplay of factors that influence Estonian parents' choice of mediation strategies used with sons versus daughters, we conducted a series of linear regression analyses. For the sake of better generalizability we used three compound scales of parental mediation: active mediation (active mediation of internet use + active mediation of internet safety), restrictive mediation, and monitoring and technical restrictions (monitoring + technical mediation), applied also in Helsper et al. (2013). As the focus of this analysis lies on parental socialization practices and the underlying social and gender norms, we used only parents' answers as the dependent variables. All predictors introduced in the section on Measures were tested; only those that were significant in at least one model were included in the final regression models (Table 3 ).

Table 3. Predictors of Parental Mediation in Estonia.

\begin{tabular}{|c|c|c|c|c|c|c|c|c|c|c|c|c|c|c|c|c|c|c|}
\hline & \multicolumn{6}{|c|}{ Active mediation } & \multicolumn{6}{|c|}{ Restrictive mediation } & \multicolumn{6}{|c|}{ Monitoring and technical restrictions } \\
\hline & \multicolumn{3}{|c|}{ Boys } & \multicolumn{3}{|c|}{ Girls } & \multicolumn{3}{|c|}{ Boys } & \multicolumn{3}{|c|}{ Girls } & \multicolumn{3}{|c|}{ Boys } & \multicolumn{3}{|c|}{ Girls } \\
\hline & B & SE & $\boldsymbol{\beta}$ & B & SE & $\beta$ & B & SE & $\beta$ & B & SE & $\beta$ & B & SE & $\beta$ & B & SE & $\beta$ \\
\hline (Constant) & 8.17 & 1.46 & & 6.49 & 1.48 & & 4.65 & .88 & & 5.47 & .90 & & 4.87 & .99 & & 3.07 & 1.07 & \\
\hline \multicolumn{19}{|l|}{ Demographics } \\
\hline Age of child & -.26 & .07 & $\begin{array}{l}-.20 \\
* * *\end{array}$ & -.01 & .07 & -.01 & -.29 & .04 & $\begin{array}{l}-.36 \\
* * *\end{array}$ & -.27 & .04 & $\begin{array}{l}-.34 \\
* * *\end{array}$ & -.11 & .04 & $\begin{array}{l}-.13 \\
*\end{array}$ & .06 & .05 & .07 \\
\hline Age of parent & -.05 & .02 & $\begin{array}{c}-.13 \\
* *\end{array}$ & -.07 & .02 & $\begin{array}{l}-.15 \\
* *\end{array}$ & .01 & .01 & .03 & -.00 & .01 & -.01 & -.05 & .01 & $\begin{array}{l}-.18 \\
* * *\end{array}$ & -.05 & .02 & $\begin{array}{l}-.16 \\
* *\end{array}$ \\
\hline $\begin{array}{l}\text { Language } \\
\text { (Estonian=1) }\end{array}$ & .59 & .37 & .08 & .47 & .37 & .06 & .15 & .22 & .03 & .61 & .23 & $\begin{array}{l}.13 \\
* *\end{array}$ & -.36 & .25 & -.07 & -.55 & .27 & $\begin{array}{c}-.10 \\
*\end{array}$ \\
\hline \multicolumn{19}{|c|}{ Parental confidence } \\
\hline $\begin{array}{l}\text { Confidence in } \\
\text { being able to } \\
\text { help the child }\end{array}$ & 1.26 & .20 & $\begin{array}{l}.31 \\
* * *\end{array}$ & 1.32 & .21 & $\begin{array}{l}.32 \\
* * *\end{array}$ & .52 & .12 & $\begin{array}{l}.21 \\
* * *\end{array}$ & .33 & .13 & $\begin{array}{l}.13 \\
*\end{array}$ & .56 & .13 & $\begin{array}{l}.21 \\
* * *\end{array}$ & .50 & .15 & $\begin{array}{l}.17 \\
* *\end{array}$ \\
\hline $\begin{array}{l}\text { Confidence in } \\
\text { the child's self- } \\
\text { efficacy }\end{array}$ & -.33 & .24 & -.07 & -.76 & .23 & $\begin{array}{l}-.17 \\
* * *\end{array}$ & -.27 & .14 & -.09 & -.41 & .14 & $\begin{array}{l}-.15 \\
* *\end{array}$ & -.15 & .16 & -.05 & -.20 & .17 & -.06 \\
\hline \multicolumn{19}{|c|}{$\begin{array}{l}\text { Expectations / experiences of media } \\
\text { effects }\end{array}$} \\
\hline $\begin{array}{l}\text { Parent's } \\
\text { internet-related } \\
\text { worries }\end{array}$ & .34 & .25 & .07 & .44 & .23 & .09 & .16 & .15 & .05 & .13 & .14 & .04 & .50 & .17 & $\begin{array}{l}.15 \\
* *\end{array}$ & .37 & .17 & .11 \\
\hline $\begin{array}{l}\text { Child has been } \\
\text { bothered } \\
\text { online (Yes=1) }\end{array}$ & .55 & .33 & .08 & .83 & .33 & $\begin{array}{l}.12 \\
* *\end{array}$ & -.35 & .20 & -.08 & .23 & .20 & .05 & .29 & .22 & .06 & .63 & .24 & $\begin{array}{l}.13 \\
* *\end{array}$ \\
\hline Adjusted $\mathrm{R}^{2}$ & & $.22 * * *$ & & & $.17^{* * *}$ & & & $.23^{* * *}$ & & & $.20^{* * *}$ & & & $.17^{* * *}$ & & & $.10^{* * *}$ & \\
\hline
\end{tabular}

Base: 1,000 children aged 9-16 who use the internet and one of their parents.

$* p<0.05,{ }^{* *} p<0.01, * * * p<0.001$.

Active parental mediation is most significantly predicted, among boys and girls alike, by parents' confidence in helping the child to cope with negative online experiences: the higher parents' confidence, the more they practice active mediation (Table 3). Parents' age is also a gender-neutral significant predictor with older parents using a smaller amount of mediation activities. With regard to several other independent variables, notable gender differences appear. In the case of boys, age matters: when sons become older, parents engage in significantly less activities of active mediation. When it comes to girls, their particular experiences come to play: parents pay more attention to active mediation, if their 
daughters have been bothered on the internet and when parents believe less in daughters' self-efficacy in coping with negative online experiences.

Restrictive mediation is, among both boys and girls, most strongly determined by children's age, with less restrictions applied to older sons and daughters (Table 3). Parents' self-confidence is also an important predictor of parental restrictions, slightly more so in the case of boys. Similarly to active mediation, parents' lesser trust in children's self-efficacy matters only in the case of girls, urging parents to protect their daughters by applying more restrictions. Interestingly, among girls, the family's ethnic background is a significant factor. Estonian-speaking parents are more likely to use restrictions for daughters.

Monitoring and technical restrictions are, in the case of boys and girls alike, significantly predicted by parents' higher self-confidence and younger age as well as their higher level of being worried about children's potential negative online experiences (Table 3). Similar to active mediation, children's younger age mattered only in the case of sons, while previous harmful experiences on the internet predict parental monitoring and technical mediation only among daughters. In the case of girls, ethnic background has a small effect. In families where Estonian is not spoken as a main language, more monitoring and technical restrictions are applied to daughters.

In general, while the gender of child or parent does not predict the extent of the three main types of mediation, Estonian parents appear to be guided by somewhat different considerations when applying mediation strategies for sons versus daughters. In the case of boys, their age and parents' self-confidence play the main role. Parents use more mediation for younger sons and practice more activities when they feel confident to do so. In the case of girls, their particular online experiences are an important factor. Parents do more if their daughters have been bothered on the internet and when parents believe less in daughters' ability to cope with negative online experiences. Furthermore, ethnic background plays a more significant role in the case of girls.

\section{In-Depth Analysis of Estonian Mothers' Perspectives}

In the following section, we present the results of the qualitative analysis of Estonian mothers' views on parental mediation. We have divided this section into four parts, based on the types of parental mediation discussed most actively. The section will demonstrate that for Estonian mothers the most problematic issues related to children's gender and age are excessive internet use, inappropriate content, safety problems, and parent's right to monitor children's online activities.

\section{Time management}

Struggles with time management of children's computer use and their parents' concern about children spending too much time on the computer were the most important topics in both focus groups. Most of the mothers admitted that setting clear rules was almost impossible, because children use the internet mostly on smartphones and when parents are not at home. Therefore, rigid time constraints seem to lose importance in parental mediation. Nevertheless, 'time panic' seems to be more relevant for boys compared with girls. The following quotes demonstrate that boys' mothers tend to be especially distressed about excessive internet use (F1.5B10), while girls' lengthy online activities are reflected in a much smoother manner (F1.9G10).

He would spend all of his free time on the internet. He would not do anything else... Ok, maybe once in a week would take his Legos and play... and maybe if a new volume of the magazine that he likes will arrive... probably he would not go to computer, but read this first, but yes, otherwise he would spend all of his free time on the internet.

(F1.5B10)

Last summer when it was raining, they could watch these serials twelve hours long. (F1.9G10)

Most of the families do not use technical parental controls to set time limits, but instead follow the clock and tell the child when the time is over. Many mothers admitted that this kind of control was not efficient as the child mostly uses the internet without parents being present. Thus, mothers are trying to set the time limits at least on home PCs, but implement the rules quite differently for boys and girls. Boys are managed in a far more authoritarian and disciplinary way compared to girls. Time constraints and parental control over them are very strict for boys (F1.8B9), but missing at all, being negotiable or 'floating' in the case of girls (F1.7G12). 
We have serious rules, one hour per day... and I go around with a whip, if time is up, the computer shuts down!

(F1.8B9)

Well, we have set the rule for one hour per day, but it takes more time ... ALWAYS... they finally stop when I start grumbling... otherwise it can go over half an hour... even two hours. (F1.7G12)

\section{Content management}

Another important issue is connected with children's online activities and problematic internet content. Most of the children, regardless of their gender, play games, chat with friends, watch videos, listen to music, do schoolwork, etc. online. Their mothers' acceptance of these activities, however, depends largely on children's gender. Mothers are deeply worried about children's problematic activities, in particular about gaming, which tends to be considered more problematic in the case of boys, especially because of the impact of violent content (F2.5B12) while girls' mothers seem to 'forget' or downplay the violent nature by referring to other qualities of the game (F1.7G12).

His brain is degenerating, that's the main damage. How normal can a person be, if he is running in bushes like a Vietcong soldier for four hours to kill Americans... or watches these stupid YouTube movies for hours?

(F2.5B12)

Mine are going on this TransforMice. There, some mice are beating each other, but my older daughter is a serious doer there, because she is kind of artist who draws profiles for these characters. She has created the portfolio and others can order a character from her and they are giving compliments to her, etc.

(F1.7G12)

Instead of playing games and watching videos that mothers regard as pure entertainment or just spending time online, they encourage their children to use the internet for more useful purposes. While using computer for schoolwork or searching information for one's interests are gender-neutral competencies, boys tend to be recognized for using the internet for hobbies more than girls are. In particular, boys' mothers praise and even laud their sons for being mature in doing something extraordinary compared with peers (F1.5B10). Girls' mothers, on the contrary, encourage matureness mostly in practical activities (F1.7G12).

I have accepted, if he is just listening to music or music is playing, when he is working or doing something else on computer. He sometimes posts his music links to Facebook, which is not meaning much to others in his age... like jazz stuff...

(F1.5B10)

Well... she definitely reads Postimees [Estonian daily]. She definitely understands that the internet means more than Facebook and if she needs to prepare a document on computer, she knows how to do it... to change fonts and style, for example. And, I have asked her to write to the library and extend the due date of the borrowed books.

(F1.7G12)

\section{Safety management}

Mothers admitted to the lack of clear rules in families about when to talk with children about online risks and safety. Parents mostly start with active mediation of internet safety when they realize that the child is more engaged in activities that may have negative consequences, or when something bothers the child on the internet. Still, parents employ quite different approaches to boys and girls. In the case of boys, we would call this 'parent-initiated general instructions,' which means that parents mostly talk about internet risks that are essential for parents themselves and also highlighted by the media (F2.5B12); for the child such instructions do not necessarily comprise any new information (F2.3B12).

Of course, we have talked about protection of personal data and about net perverts and other kind of dangerous things, so that it already bores everyone.

(F2.5B12) 
Well, there is not anything new, when the child started to spend more time on the internet, we talked with him and from time to time we bore him with repeating this, after what an annoyed sigh 'Yeeeees, I knooooow!' is coming.

(F2.3B12)

In the case of girls, talking about internet safety and problematic online behaviour is taken more seriously, and it is more thorough and 'case-specific' compared to boys. Girls' mothers initiate these talks, when they have heard about specific incidents in the media, or when a negative incident has occurred with other children they know (F1.9G10). Girls' mothers also take potentially harmful situations very seriously and give advice before something bad could actually happen (F1.6G12). Still, mothers also admitted uncertainty and confusion in giving such advice, and some mothers felt quite helpless (F1.7G12).

Well, we had the case about girls who made the fake account with the name of another girl and used her identity to send nasty messages and so on. Then I talked seriously with my own daughter about it.

(F1.9G10)

I told her, when you want to meet someone, then some places are safe and some are not. Public places are safe, but some kind of private holiday cottages are not safe. If somebody whom you barely know on the internet invites you to a private birthday party where nobody's parents are present, then sorry, but you cannot go there.

(F1.6G12)

M. had a friend whom she wanted to meet. And she asked if I agree. Well... me of course... hands shaking and did not know what to do. She is quite big already and the boy is of the same age... But finally... by a lucky chance, it was called off, I mean, they did not meet... (F1.7G12)

\section{Monitoring}

Mothers monitor children's online activities, especially social networking, quite actively. This type of mediation is strongly age-specific, being more actively used on younger children, as well as genderspecific. In the case of girls, mothers admitted that they often checked Facebook accounts either through having a common account with their daughter (F1.9G10) or by accepting the daughter's friends to keep an eye on what was happening in her network (F1.2G11).

We have common account on $F B$, of course it is mainly my daughter's account, but because she is too young for having her own account, we created this one, and she has to agree that I control and follow her activities there. This was my precondition that she could use FB at all. (F1.9G10)

My daughter's friends have asked me to accept their friend requests on $F B$, and I have accepted all of them, so I have a very good overview what's going on there.

(F1.2G11)

In the case of boys, monitoring is more secretive and non-direct. Some mothers strongly object to monitoring as they completely trust the child (F1.5B10). In particular, mothers of older boys regard monitoring as non-appropriate, because the child needs some privacy and a 'parent-free zone'.

I do not check anything; my kid is so antisocial... it is unimportant for me to check what is going on in his FB... we have separate computers and do not know his FB password, anyway... and I think it is not a problem at all.

(F1.5B10)

\section{Discussion}

The macro-level findings of this study, somewhat surprisingly, refer to a pattern of positive correlations between the number of gender differences in parental mediation, indicators of gender equality, and the broadband penetration rate, giving rise to the hypothetical explanation that an earlier and more extensive diffusion of online technologies may have provided parents with more time and opportunities to adopt different mediation strategies for boys and girls. Furthermore, greater gender sensitivity in public 
discourses (including those concerning children's online lives) and a bigger involvement of male caregivers in the socialization process may have contributed to the emergence of more gender-nuanced approaches to parental mediation. This explanation is partially supported by the proposed classification of countries, based on gender characteristics of parental mediation. The position of all post-socialist countries and most of the social democratic states is well interpretable in terms of the broadband penetration rates in those countries and the underlying welfare and gender regimes (Kalmus \& Roosalu, 2012). In many other countries gender patterns of parental mediation are, first, still emerging and, second, depend on many other culture-specific and covert factors, calling for further and more detailed research.

More specific analysis of gendered parental mediation in Estonia shows that parents' use of different mediation strategies does not depend purely on children's gender, but on a more complex interrelation of gender and children's and parents' socio-demographic characteristics and parent-child interactions. In discussing the findings, we also have to keep in mind that the majority of respondents in both quantitative and qualitative parts of our study were women, which is important in terms of inter-gender and intragender interactions, namely between mother and child.

Our study adds details to relatively scarce knowledge of gendered socialization practices in a particularly dynamic socialization context, such as mediation of internet use, and proposes answers to the question concerning how gender norms and changes in socialization values shape the upbringing of boys and girls. Estonia, as a country undergoing multiple societal changes, proved as a good example to answer this question. Our results support the findings of previous studies arguing that in the context of social transformation parents struggle between old and new parenting paradigms in supporting traditional socialization values while trying to adapt their parenting practices to rapid changes in society (Tulviste et al., 2012). In our qualitative results, mothers, on the one hand, tended to hold traditional authoritarian ways of parenting, but on the other hand felt themselves unconfident and troubled when it came to finding alternative parenting methods, which, in some cases, resulted in a passive approach to mediation. Nevertheless, we found that parenting styles depend on children's gender and, thus, gender norms. Boys' mothers apparently feel that their sons should be 'toughened up' with discipline and control (Kimmel, Hearn, \& Connell, 2005), and therefore they tried to follow a rather authoritarian style, while girls are raised by more liberal and free-flowing rules, except when it comes to their safety.

Parenting style also depends on the children's age. Our results show that children's age is a strong predictor of nearly all mediation activities, being more significant in the case of boys. Authoritarian parenting is especially visible in the case of younger boys (e.g. in setting time constraints). When boys get older, the parenting style shifts to the other side of the spectrum, with all types of mediation losing importance. Presumably, this transformation of parenting style is happening faster in the case of boys due to a gender norm according to which boys are expected to become independent and take responsibility earlier than girls, especially in the context of male-dominated tech-savvy computer culture (Henwood, Plumeridge, \& Stepulevage, 2000).

\section{Implications}

Previous research (e.g. Livingstone \& Helsper, 2008) has emphasized differences between parents' and children's views about reasonable media use. Adults employ digital technologies in a more instrumental way whereas children use them mainly for fun and social reasons. In our study, different perspectives of children's and parents' generations become particularly visible in content management practices where mothers tried to minimize children's entertainment-related activities, being especially negative toward boys' 'game culture', and encouraging more adult-like online activities. Living in separate media worlds also seems to be a problem in the mediation of internet safety where mothers, although being generally informed of internet risks, are quite passive in parent-child interactions to pick up potentially harmful online experiences for children. Instead, Estonian parents tend to use retroactive mediation (Kalmus et al., 2012), particularly in the case of girls, reacting mostly when something has bothered the child online.

On the positive side, one of the most significant predictors of all types of parental mediation is parents' confidence to help the child, especially in the case of boys. Taking into account that younger parents use more active mediation and monitoring and technical solutions gives reason to foresee the narrowing of the generational and cultural gaps in the future. Nevertheless, to foster the development of parents' selfconfidence and, thus, their ability to provide more gender- and age-appropriate, and pro-active rather than retroactive mediation to their children, continued efforts to raise awareness among parents on internet risks and suitable ways to deal with these might be a social intervention needed to accelerate the way forward. In particular, further crystallisation of interaction processes between parents and children is necessary in the countries such as Estonia (Helsper et al., 2013). Furthermore, as gender represents an important aspect of socialization, the development of more gender-sensitive strategies of parental 
mediation may contribute to a greater acknowledgment of more egalitarian gender norms, and to finding balance between old and new socialization paradigms.

\section{Limitations}

A combined use of quantitative and qualitative methods helped us to add explanations and accentuations, stemming from the interviews, to broad patterns found in quantitative analysis. Although the homogeneity of focus groups provided us with rich data about children's and parents' interactions, future research would benefit from more wide-scale comparisons based on a bigger variety in focus group participants' socio-economic background.

\section{Acknowledgements}

This article draws on the work of the EU Kids Online network funded by the EC (DG Information Society) Safer Internet Plus Programme (project code SIP-KEP-321803); see www.eukidsonline.net, and was supported by the grants from the Estonian Research Council (ETF 8527) and the Estonian Ministry of Education and Research (IUT 20-38). The authors gratefully acknowledge Katrin Romanenkov for conducting and transcribing the focus group interviews.

\section{References}

Aavik, K., \& Uusma, H. (2014). Laste sotsialiseerimine, kogumikus Soolise võrdõiguslikkuse monitooring 2013 [Socialisation of children. In T. Roosalu (Ed.), Gender Equality Monitoring 2013] (pp. 26-36).

Sotsiaalministeeriumi toimetised 3/2014. Retrieved from: http://www.sm.ee/sites/default/files/contenteditors/Ministeerium_kontaktid/Uuringu_ja_analuusid/Sotsiaalvaldkond/sooline_vo_monitooring_2013_ve eb.pdf

Bohle, D., \& Greskovits, B. (2007). Neoliberalism, embedded neoliberalism and neocorporatism: Towards transnational capitalism in Central-Eastern Europe. West European Politics, 30, 443-466.

http://dx.doi.org/10.1080/01402380701276287

Chakroff, J. L., \& Nathanson, A. I. (2011). Parent and school interventions: Mediation and media literacy. In S. L. Calvert \& B. J. Wilson (Eds.), The Handbook of children, media, and development (pp. 552-576). Chichester: Wiley-Blackwell.

Eastin, M. S., Greenberg, B. S., \& Hofschire, L. (2006). Parenting the internet. Journal of Communication, 56, 486-504. http://dx.doi.org/10.1111/j.1460-2466.2006.00297.x

Flick, U. (2014). An introduction to qualitative research. London: Sage Publications.

Görzig, A. (2012). Methodological framework: the EU Kids Online project. In S. Livingstone, L. Haddon, \& A. Görzig (Eds.), Children, risk and safety online: Research and policy challenges in comparative perspective (pp. 15-32). Bristol: The Policy Press.

Hedström, P., \& Swedberg, R. (1998). Social mechanisms: An analytical approach to social theory. Cambridge: Cambridge University Press.

Helsper, E. J., Kalmus, V., Hasebrink, U., Sagvari, B., \& de Haan, J. (2013). Country classification: Opportunities, risks, harm and parental mediation. London: EU Kids Online. Retrieved from:

http://eprints.Ise.ac.uk/52023/

Henwood, F., Plumeridge, S., \& Stepulevage, L. (2000). A tale of two cultures? Gender and inequality in computer education. In S. Wyatt, F. Henwood, N. Miller, \& P. Senker (Eds.), Technology and in/equality: Questioning the information society (pp. 111-128). London: Routledge.

Järviste, L. (2010). Gender equality and inequality: Attitudes and situation in Estonia in 2009. Series of the Ministry of Social Affairs, 3/2010. Retrieved from: http://www.gwi-

boell.de/sites/default/files/assets/gwi-boell.de/images/downloads/series_20103eng.pdf 
Kalmus, V. (2012). Making sense of the social mediation of children's internet use: Perspectives for interdisciplinary and cross-cultural research. In C. W. Wijnen, S. Trültzsch, \& C. Ortner (Eds.), Medienwelten im Wandel: Kommunikationswissenschaftliche Positionen, Perspektiven und Konsequenzen. Festschrift für Ingrid Paus-Hasebrink [Changing Media Worlds: Positions, Perspectives and Consequences in Communication Science. Festschrift in Honour of Ingrid Paus-Hasebrink] (pp. 137-149). Wien: Springer.

Kalmus, V. (2013). Children's safety in the new media environment. In M. Heidmets (Ed.), Estonian Human Development Report 2012/2013: Estonia in the World (pp. 92-94). Tallinn: Estonian Cooperation Assembly. Retrieved from: http://www.kogu.ee/wp-content/uploads/2013/05/EIA2013_eng.pdf

Kalmus, V., \& Roosalu, T. (2012). Institutional filters on children's internet use: An additional explanation of cross-national differences in parental mediation. In M. Walrave, W. Heirman, S. Mels, C. Timmerman, \& H. Vandebosch (Eds.), E-youth: Balancing between opportunities and risks (pp. 234-250). Brussels: Peter Lang.

Kalmus, V., von Feilitzen, C., \& Siibak, A. (2012). Effectiveness of teachers' and peers' mediation in supporting opportunities and reducing risks online. In S. Livingstone, L. Haddon, \& A. Görzig (Eds.), Children, risk and safety on the internet: Research and policy challenges in comparative perspective ( $\mathrm{pp}$. 245-256). Bristol: The Policy Press.

Kimmel, M., Hearn, J., \& Connell, R. W. (2005). Handbook of studies on men and masculinity, London: Sage Publications.

Kirwil, L. (2009). Parental mediation of children's internet use in different European countries. Journal of Children and Media, 3, 394-409. http://dx.doi.org/10.1080/17482790903233440

Kirwil, L., Garmendia, M., Garitaonandia, C., \& Martínez Fernández, G. (2009). Parental mediation. In S. Livingstone \& L. Haddon (Eds.), Kids online: Opportunities and risks for children (pp. 199-215). Bristol: Policy Press.

Kutsar, D., Kasearu, K., \& Kurrikoff, T. (2012). Family trends and changing parenting practices in Estonia. Cognition, Brain, Behaviour: An Interdisciplinary Journal, 16, 171-190.

Lauristin, M. (1997). Context of transition. In M. Lauristin, P. Vihalemm, K. E. Rosengren, \& L. Weibull (Eds.), Return to the western world. Cultural and political perspectives on the Estonian post-communist transition (pp. 25-40). Tartu, Estonia: Tartu University Press.

Lauristin, M. (2003). Social contradictions shadowing Estonia's 'success story'. Demokratizatsiya, 11, 601616.

Livingstone, S., Haddon, L., Görzig, A., \& Ólafsson, K. (2011). Risks and safety on the Internet: the perspective of European children. Full findings. LSE London: EU Kids Online. Retrieved from: http://eprints.Ise.ac.uk/33731/

Livingstone, S., \& Helsper, E. J. (2008). Parental mediation of children's internet use. Journal of Broadcasting and Electronic Media, 52, 581-599. http://dx.doi.org/10.1080/08838150802437396

Livingstone, S., Kalmus, V., \& Talves, K. (2014). Girls' and boys' experiences of online risk and safety. In C. Carter, L. Steiner, \& L. McLaughlin (Eds.), The Routledge Companion to Media and Gender (pp. 190200). London: Routledge.

Mayring, P. (2000). Qualitative content analysis. Forum Qualitative Sozialforschung / Forum: Qualitative Social Research,1(2), Art. 20. Retrieved from: http://nbnresolving.de/urn:nbn:de:0114-fqs0002204

Morgan, D. L. (1997). Focus groups as qualitative research (2nd ed). London: Sage Publications

Nikken, P., \& Schols, M. (2015). How and why parents guide the media use of young children? Journal of Child and Family Studies. http://dx.doi.org/10.1007/s10826-015-0144-4

Patton, M. Q. (2002). Qualitative research and evaluation methods (3rd ed). London: Sage Publications. 
Paus-Hasebrink, I., Ponte, C., Dürager, A., \& Bauwens, J. (2012). Understanding digital inequality: the interplay between parental socialisation and children's development. In S. Livingstone, L. Haddon, \& A. Görzig (Eds.), Children, risk and safety on the internet: Research and policy challenges in comparative perspective (pp. 257-271). Bristol: The Policy Press.

Raudsepp, M., Tart, I., \& Heinla, E. (2013). Post-socialist dynamics of value patterns in Estonia. Studies of Transition States and Societies, 5(2), 35-51. Retrieved from:

http://publications.tlu.ee/index.php/stss/article/view/162

Rosen, L. D., Cheever, N. A., \& Carrier, L. M. (2008). The association of parenting style and child age with parental limit setting and adolescent MySpace behavior. Journal of Applied Developmental Psychology, 29, 459-471. http://dx.doi.org/10.1016/j.appdev.2008.07.005

Soo, K., Ainsaar, M., \& Kalmus, V. (2012). Behind the curtains of e-state: Determinants of online sexual harassment among Estonian children. Studies of Transition States and Societies, 4(2), 35-48. Retrieved from: http://publications.tlu.ee/index.php/stss/article/view/95

Trost, J. (1986). Statistically nonrepresentative stratified sampling: A sampling technique for qualitative studies. Qualitative Sociology, 9(1), 54-57. http://dx.doi.org/10.1007/BF00988249

Tulviste, T., Mizera, L., \& De Geer, B. (2012), Socialization values in stable and changing societies: a comparative study of Estonian, Swedish and Russian Estonian mothers. Journal of Cross-Cultural Psychology, 43, 480-497. http://dx.doi.org/10.1177/0022022111401393

van de Vijver, F. J. R., \& Leung, K. (2011). Equivalence and bias: a review of concepts, models, and data analytic procedures. In D. Matsumoto, \& F. J. R. van den Vijver (Eds.), Cross-cultural research methods in psychology (pp. 17-45). New York: Cambridge University Press.

Vis, B., van Kersbergen, K., \& Becker, U. (2008). The politics of welfare state reform in the Netherlands: Explaining a never-ending puzzle. Acta Politica, 43, 333-356. http://dx.doi.org/10.1057/ap.2008.11 


\section{Appendix}

Table A1. Gender Differences in Parental Mediation in Estonia (index means and \%).

\begin{tabular}{|c|c|c|c|c|}
\hline & \multicolumn{2}{|c|}{ Children's answers } & \multicolumn{2}{|c|}{ Parents' answers } \\
\hline & Boys & Girls & Boys & Girls \\
\hline Active mediation of internet use: Parents sometimes... & 2.09 & 2.24 & 2.49 & 2.48 \\
\hline Talk to the child about what the child does on the internet & 63 & 66 & 78 & 78 \\
\hline Stay nearby when the child uses the internet & 45 & 47 & 46 & 46 \\
\hline Encourage the child to explore and learn things on the internet on their own & 36 & 42 & 48 & 49 \\
\hline Sit with the child when they use the internet & 32 & 29 & 35 & 35 \\
\hline Do shared activities together with the child on the internet & 34 & 38 & 47 & 44 \\
\hline Active mediation of internet safety: Parents have... & 3.11* & $3.38 *$ & 3.58 & 3.69 \\
\hline Explained why some websites are good or bad & $61^{* *}$ & $64^{* *}$ & 69 & 73 \\
\hline Helped the child when something is difficult to do or find on the internet & 68 & 71 & 66 & 68 \\
\hline Suggested ways to use the internet safely & $54^{*}$ & $55^{*}$ & 65 & 61 \\
\hline Suggested ways to behave towards other people online & 48 & 49 & 61 & 63 \\
\hline Talked to the child about what to do if something on the internet bothered them & $43^{*}$ & $52^{*}$ & 54 & 54 \\
\hline Helped the child in the past when something has bothered them on the internet & $37^{* *}$ & $46^{* *}$ & 43 & 48 \\
\hline Restrictive mediation: Rules apply about whether the child can... & 1.53 & 1.48 & 2.07 & 2.16 \\
\hline Give out personal information to others on the internet & 52 & 55 & 62 & 64 \\
\hline Upload photos, videos or music to share with others & 34 & 33 & $51^{* *}$ & $53^{* *}$ \\
\hline Download music or films on the internet & 24 & 24 & 34 & 37 \\
\hline Have their own social networking profile & 17 & 15 & 24 & 23 \\
\hline Watch video clips on the internet & $11^{*}$ & $10^{*}$ & $16^{*}$ & $17^{*}$ \\
\hline Use instant messaging & 13 & 10 & 17 & 19 \\
\hline Monitoring: Parents check... & $0.82 * *$ & $1.05 * *$ & 1.35 & 1.46 \\
\hline Which websites the child visited & 37 & 43 & 49 & 46 \\
\hline The child's profile on a social network or online community & $23^{* *}$ & $34 * *$ & 30 & 35 \\
\hline Which friends or contacts the child adds to social networking profile & 24 & 27 & 38 & 44 \\
\hline The messages in the child's email or instant messaging account & 18 & 15 & 23 & 25 \\
\hline Technical mediation: Parents use... & $1.03 * *$ & $1.18^{* *}$ & 1.35 & 1.29 \\
\hline Software to prevent spam/junk mail or viruses & 78 & 83 & 84 & 85 \\
\hline Parental controls or other means of blocking or filtering some types of website & 9 & 12 & 16 & 16 \\
\hline Parental controls or other means of keeping track of the websites the child visits & 9 & 13 & 21 & 20 \\
\hline A service or contract that limits the time the child spends on the internet & 5 & 6 & 8 & 9 \\
\hline
\end{tabular}

Base: 1,000 children aged 9-16 who use the internet and one of their parents. Four questions about technical mediation were asked of 11-16 yearold children only.

* Difference between boys and girls is significant at the 0.05 level (based on $t$ or $\chi^{2}$ statistic), ** Difference between boys and girls is significant at the 0.01 level (based on $t$ or $\chi^{2}$ statistic). 
Table A2. Gender Differences in Parental Mediation in 25 European Countries.

\begin{tabular}{|c|c|c|c|c|c|c|c|c|c|c|c|c|}
\hline \multirow[t]{2}{*}{ Country } & \multicolumn{2}{|c|}{$\begin{array}{l}\text { Active } \\
\text { mediation of } \\
\text { internet use (0- } \\
\text { 5) }\end{array}$} & \multicolumn{2}{|c|}{$\begin{array}{l}\text { Active mediation } \\
\text { of internet } \\
\text { safety }(0-6)\end{array}$} & \multicolumn{2}{|c|}{$\begin{array}{l}\text { Restrictive } \\
\text { mediation (0- } \\
6)\end{array}$} & \multicolumn{2}{|c|}{$\begin{array}{l}\text { Monitoring } \\
(0-4)\end{array}$} & \multicolumn{2}{|c|}{$\begin{array}{l}\text { Technical } \\
\text { mediation (0- } \\
4)\end{array}$} & \multirow[t]{2}{*}{$\begin{array}{l}\text { Number of } \\
\text { significant } \\
\text { gender } \\
\text { differences }\end{array}$} & \multirow[t]{2}{*}{$\begin{array}{l}\text { Number of in- } \\
\text { consistent child- } \\
\text { parent index } \\
\text { pairs }\end{array}$} \\
\hline & 을 & $\frac{\stackrel{2}{0}}{\frac{1}{\pi}}$ & $\frac{\overline{0}}{\overline{\mathrm{U}}}$ & 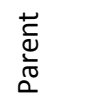 & $\frac{\overline{0}}{\overline{\mathrm{C}}}$ & $\frac{\vec{c}}{\frac{\pi}{2}}$ & $\frac{\overline{\frac{C}{\mathrm{U}}}}{\mathrm{U}}$ & $\frac{\vec{c}}{\frac{\pi}{0}}$ & $\frac{7}{\bar{C}}$ & $\frac{\vec{c}}{\frac{\pi}{2}}$ & & \\
\hline Austria & & & & & Girls & Girls & & & & & 2 & 0 \\
\hline Belgium & & & & Girls & Girls & Girls & & Girls & & & 4 & 2 \\
\hline Bulgaria & Girls & Girls & & Girls & & & & & & & 3 & 1 \\
\hline Cyprus & & & & & & & & & & & 0 & 0 \\
\hline $\begin{array}{l}\text { Czech } \\
\text { Republic }\end{array}$ & & & Girls & & & & & & & & 1 & 1 \\
\hline Finland & & & & & & & & Boys & & Boys & 2 & 2 \\
\hline France & & & & & & & & & & & 0 & 0 \\
\hline Germany & & & Girls & Girls & & & & & & & 2 & 0 \\
\hline Greece & & & & & & & Girls & & & Boys & 2 & 2 \\
\hline Hungary & & & & & & & & & & & 0 & 0 \\
\hline Ireland & & & Girls & Girls & & & Girls & Girls & & & 4 & 0 \\
\hline Italy & & & & & & Girls & & & & & 1 & 1 \\
\hline Lithuania & & & & & & Boys & & & & Boys & 2 & 2 \\
\hline Netherlands & Girls & & Girls & Girls & & & Girls & Girls & Girls & & 6 & 2 \\
\hline Norway & Girls & & Girls & Girls & & & Girls & Girls & Boys & & 6 & 2 \\
\hline Turkey & & & & & Girls & Girls & & & Boys & & 3 & 1 \\
\hline UK & & & & & & & & & & & 0 & 0 \\
\hline
\end{tabular}

Base: 25,142 children aged 9-16 who use the internet and one of their parents. Cells show the group with significantly higher mean value of the respective index $(p<0.05)$.

${ }^{1} 11-16$ years only.

\section{Correspondence to:}

\section{Kairi Talves}

Institute of Social Studies

Faculty of Social Sciences and Education

University of Tartu

Lossi St 36, 51003, Tartu, ESTONIA

Email: kairi.talves@ut.ee 


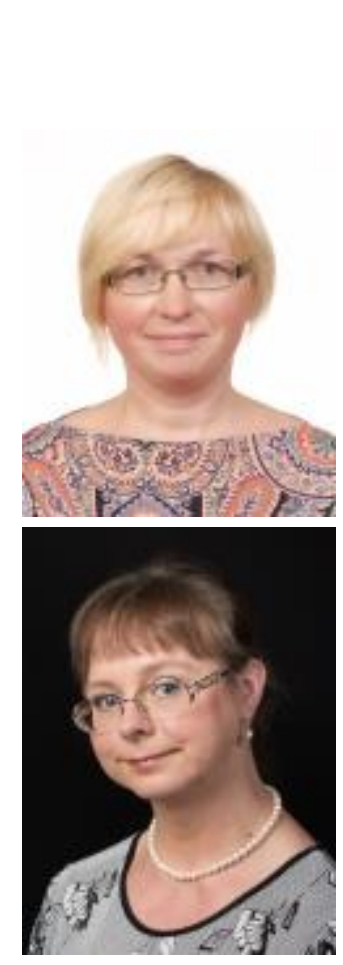

\begin{abstract}
About author(s)
Kairi Talves is currently working on her PhD thesis in Sociology at the University of Tartu, Estonia. Her main fields of research are related to gender studies, more specifically to gendered patterns of parental behaviour and their impact on socialization and intergenerational relations. She has participated in several international research projects, focusing on gender inequalities, and she has published a number of research papers in academic journals and chapters in edited volumes.
\end{abstract}

Veronika Kalmus is a Professor of Sociology at the Institute of Social Studies, University of Tartu, Estonia. Her research focuses on socialization, inter-generational relationships, media use and cultural values. She leads several research projects, including "Generations and inter-generational relations in the emerging information society," and participates in the project EU Kids Online. She has published extensively in international journals and collections, including Childhood, Children \& Society, Discourse \& Society, and Journal of Computer-Mediated Communication. 